\title{
Quando homens e mulheres assumem a direção: as diferenças de gênero na gestão escolar
}

\author{
Carliene Freitas da Silva Bernardes \\ Universidade Federal do Tocantins - UFT, Brasil \\ Universidade de Uberaba - UNIUBE, Brasil \\ Selva Fonseca Guimarães \\ Universidade de Uberaba - UNIUBE, Brasil \\ Universidade Federal de Uberlândia - UFU, Brasil
}

\section{RESUMO}

Este estudo objetiva evidenciar resultados de pesquisas brasileiras sobre o perfil dos gestores escolares, especificando suas marcas de gênero. Dado a inexistência de relatórios de pesquisa do Ministério da Educação que tratassem do perfil dos gestores escolares, buscou-se por pesquisas empíricas e documentos governamentais, na área da Educação, que versassem sobre o tema. As pesquisas que desvelaram o perfil dos dirigentes escolares se basearam nos microdados do Sistema de Avaliação da Educação Básica - SAEB, revelando que os dirigentes escolares são tipicamente femininos, acima de quarenta anos, com formação em licenciatura, em específico, a Pedagogia; sendo providas (os) às funções, preponderantemente, por indicações (políticas e/ou técnicas) nas redes municipais de ensino ou por meio de eleição e/ou seleção nas redes estaduais e federais de ensino. Considera-se que apesar da maioria dos postos de gestão serem ocupados por mulheres, os estudos revelam fortes marcas de desigualdade de gênero, tanto no acesso como no exercício da gestão.

PALAVRAS-CHAVE: Gestão escolar. Diretores. Perfil. Gênero. Diferenças.

\section{WHEN MEN AND WOMEN ASSUME THE DIRECTION: GENDER DIFFERENCES IN SCHOOL MANAGEMENT}

\begin{abstract}
This article aims to analyze the educational policy of the National Program of Professional Integration in the Modality of Education of Young and Adults - PROEJA, instituted by Decrees No. 5.478 of July 24, 2005 and No. 5.840 of July 13, 2006. In this study, are presented the trajectory of Youth and Adult Education in Brazil, a contextualization of Lula's Government political arena, the conceptions and principles established in PROEJA, the Base Document and the actions arising from the agenda construction stages, policy formulation and implementation of PROEJA. The study was carried out in documentary and bibliographical sources, allowing to establish an overview of the advances of PROEJA in the last few years.
\end{abstract}

KEYWORDS: School management. Directors. Profile. Gender. Differences.

\section{CUANDO HOMBRES Y MUJERES ASUMEN LA DIRECCIÓN: LAS DIFERENCIAS DE GÉNERO EN LA GESTIÓN ESCOLAR}




\section{RESUMEN}

Este estudio objetiva evidenciar resultados de investigaciones brasileñas sobre el perfil de los gestores escolares, especificando sus marcas de género. En cuanto a la inexistencia de informes de investigación del Ministerio de Educación que tratase del perfil de los gestores escolares, se buscó por investigaciones empíricas y documentos gubernamentales, en el área de la Educación, que versaran sobre el tema. Las investigaciones que desvelaron el perfil de los dirigentes escolares se basaron en los microdatos del Sistema de Evaluación de la Educación Básica SAEB, revelando que los dirigentes escolares son típicamente femeninos, por encima de cuarenta años, con formación en licenciatura, en específico, la Pedagogía; (a) las funciones, preponderantemente, por indicaciones (políticas y / o técnicas) en las redes municipales de enseñanza o por medio de elección y / o selección en las redes estatales y federales de enseñanza. Se considera que a pesar de que la mayoría de los puestos de gestión son ocupados por mujeres, los estudios revelan fuertes marcas de desigualdad de género, tanto en el acceso como en el ejercicio de la gestión.

PALABRAS CLAVE: Gestión escolar. Directores. Perfil. Género. Diferencias.

\section{INTRODUÇÃO}

Ao longo da nossa trajetória profissional vivenciamos algumas situações de desigualdades, que nos fazem refletir, cotidianamente, sobre a concepção do feminino, sobre a inserção da mulher no mercado de trabalho, em específico, nas funções de liderança, e sobre as políticas públicas de apoio à mulher. Numa ocasião, orientando uma equipe de uma empresa privada do ramo da construção civil sobre atendimento ao cliente, havendo predomínio de colaboradores do sexo masculino, o diretor da empresa indagou diante da minha liderança "se mulher não tinha só um neurônio"; ou ainda, outros funcionários homens e mulheres indagavam se eu era protegida de algum diretor. Noutra ocasião, na eleição para a gestão da saúde mental de um município do Estado de Minas Gerais, a equipe de psicólogos, em sua maioria feminina, elegeu um homem para a função. À época, ouviu-se frases como: "só um homem para dar conta de um bando de mulheres". Para finalizar, lembro-me dos questionamentos dos colegas, homens e mulheres, à liderança da diretora de um campus universitário, deslegitimando sua gestão: "precisa ter pulso firme", "chegar mais", "é muito calma, quer dialogar em tudo", "está noutro momento, tem os pais velhos e o filho para cuidar".

Partindo de uma representação pessoal que a Escola seria um espaço democrático, de formação e de superação das desigualdades sociais e por saber que há um predomínio de docentes do sexo feminino, nos indagamos sobre várias questões ${ }^{1}$ : se a gestão escolar tem gênero, se as mulheres empreendem práticas de gestão diferentes dos homens, se são legitimadas por seus pares, eminentemente femininos, dentre outras.

\footnotetext{
${ }^{1}$ As problematizações propostas neste estudo, compõe o projeto de pesquisa da tese de doutoramento da autora.
} 
Em busca de respostas, empreendemos uma pesquisa no site do Ministério da Educação - ME acerca de relatórios de pesquisa sobre o perfil das (os) diretoras (es) das unidades de ensino da Educação Básica, principalmente, nas pesquisas que o INEP - Instituto Nacional de Educação e Pesquisa Anísio Teixeira realiza, como o Censo Escolar e o Sistema de Avaliação da Educação Básica - SAEB. Encontramos apenas relatórios sobre o perfil do corpo docente na Educação Básica, sem especificar suas funções na gestão. Também averiguamos no Programa de Formação Continuada "Escola de Gestores da Educação Básica", ofertado pelo Ministério da Educação em nível de pós-graduação e nenhum compilado de dados sobre o perfil das (os) gestoras (es) foi encontrado.

Ora, a motivação por respostas ainda ficou mais aguçada diante da inexistência de um relatório, por parte do ME, sobre o perfil das (os) gestoras (es) escolares. Logo, direcionamos nossas buscas por pesquisas na área da Educação que versassem sobre o tema, utilizando a plataforma do Google Scholar, utilizando descritores como "gestão escolar"; "perfil gestores/diretores escolares", "gênero e gestão escolar". Foram encontrados estudos relevantes ${ }^{2}$ sobre o perfil dos (as) gestores (as) escolares que se basearam nos microdados contidos nas avaliações do SAEB, especificamente na Prova Brasil; e outros estudos que se basearam em dados regionais compilados através de instrumentos desenvolvidos pelos pesquisadores interessados na gestão educacional/escolar.

Diante desse contexto, o objetivo deste trabalho é apresentar resultados de pesquisas brasileiras sobre o perfil dos (as) gestores (as) escolares, especificando suas marcas de gênero.

Para responder o objetivo, empreendemos uma pesquisa documental e bibliográfica, buscando em documentos governamentais, em documentos jurídicos nacionais e estaduais sobre Educação, bem como em pesquisas publicadas em revistas científicas brasileiras dados para subsidiar nossa problemática.

Para Marconi e Lakatos (2010), a pesquisa bibliográfica ou de fontes secundárias, abrange toda a bibliografia relacionada a determinado tema que se tornou pública, seja ela publicada em meios escritos (revistas, jornais, livros, etc.) ou audiovisuais (rádio, televisão, filmes, etc.). No entanto, “a pesquisa bibliográfica não é mera repetição do que já foi dito ou escrito sobre certo assunto, mas propicia o exame de um tema sob novo enfoque ou abordagem, chegando a conclusões inovadoras" (MARCONI, LAKATOS, 2010, p. 166). Por sua vez, os documentos, sejam eles impressos, sonoros ou visuais, quando utilizados em conjunto com

\footnotetext{
${ }^{2}$ O Google Scholar classifica como relevante as publicações com maior número de citações na rede mundial de computadores - World Wide WEB.
} 
BERNARDES, C.F.S.; GUIMARÃES, S. F.

outras fontes de dados ou utilizados de forma exclusiva, são importantes fontes de informações para a compreensão do objeto de estudo (LAVILLE; DIONE, 2007).

Por conseguinte, este texto apresenta reflexões sobre as diferenças de gênero e sua intersecção com o mercado de trabalho; o perfil dos (as) gestores (as) escolares brasileiros a partir de marcos jurídicos e de dados sócio demográficos; uma síntese das pesquisas sobre o perfil dos gestores escolares e suas marcas de gênero; e, por fim, as considerações finais.

\section{AS DIFERENÇAS DE GÊNERO E O MERCADO DE TRABALHO}

Guacira Louro (2003) esclarece que o termo Gênero está ligado ao movimento feminista contemporâneo. Na Inglaterra, na década de 1960, além das questões políticas e sociais, o movimento feminista se preocupou com construções teóricas, levando para dentro das universidades e escolas problematizações acerca do ser mulher em diferentes instâncias e espaços. Surge assim um campo de estudos e pesquisa, os Estudos Feministas, destacando a mulher como sujeito e objeto na construção do conhecimento.

Nesse contexto, explica Louro (2003) a partir dos trabalhos de Joan Scott, que o termo Gender (Gênero) passa a ser utilizado nos estudos feministas para contrapor o termo "Sex (sexo) ou Diferença sexual" com seu determinismo biológico do que seja feminino e masculino. Com a nova linguagem, Gênero, pretendem difundir a ideia que a concepção do que seja feminino e masculino é uma construção social, sendo representada diferentemente em determinadas culturas e em determinados momentos históricos. Logo, as desigualdades de gênero precisariam ser buscadas não "nas diferenças biológicas (se é que mesmo essas podem ser compreendidas fora de sua constituição social), mas sim nos arranjos sociais, na história, nas condições de acesso aos recursos da sociedade, nas formas de representação" (LOURO, 2003, p. 22).

Além dos termos sexo e gênero a autora também esclarece sobre o termo sexualidade. A sexualidade parece ser, na visão da autora, uma dimensão mais ampla da identidade do sujeito, abarcando tanto sua identidade sexual quanto a identidade de gênero. A identidade sexual "se constituiria, pois, através das formas como vivem sua sexualidade, com parceiros/as do mesmo sexo, do sexo oposto, de ambos os sexos ou sem parceiros/as"; por outro lado "os sujeitos também se identificam, social e historicamente, como masculinos ou femininos e assim constroem suas identidades de gênero" (LOURO, 2003, p. 26), sendo ambas as identidades distintas, mas profundamente inter-relacionadas. 
Portanto, a partir dos Estudos Feministas e dos Estudos Culturais ${ }^{3}$, Louro (2003) parte de uma concepção que os sujeitos são constituídos por identidades plurais, múltiplas (identidade sexual, de gênero, de etnia, raça, classe, nacionalidade, dentre outros), identidades que se interrelacionam, se transformam e que podem até ser contraditórias.

Os Estudos Feministas pós estruturalistas (LOURO, 2003) criticam a concepção binária de Gênero, presente na sociedade e em muitos estudos teóricos, na qual a feminilidade e a masculinidade são pensadas como identidades opostas, polarizadas, fixas, regidas por lógica de dominação-submissão androcêntrica e heteronormativa. Por outro lado, defendem uma desconstrução desse pensamento e a pluralidade de gêneros, como por exemplo, existem mulheres heterossexuais, homossexuais, bissexuais, negras, brancas, índias, pobres..., homens negros, brancos, índios, homossexuais, heterossexuais, dentre outros.

A introdução sobre Gênero até aqui exposta nos leva a pensar sobre quando as diferenças são tratadas como desiguais, pois vemos ainda no cotidiano uma grande opressão ao feminino, dando como exemplo o noticiário frequente de feminicídio e a inserção da mulher no mercado de trabalho.

Analisando os relatórios do IBGE sobre a Educação no Brasil (2017) e a Síntese dos Indicadores Sociais (2018), verificamos que as condições das mulheres no mercado de trabalho são marcadas por desigualdades de gênero.

O aumento da escolarização das mulheres tem sido um ganho nos últimos anos no Brasil, segundo dados do IBGE (2017), a taxa de alfabetização e o número de anos de estudo é maior entre as mulheres que entre os homens. No entanto, a dificuldade se apresenta na inserção e manutenção no mercado de trabalho. Segundo os Indicadores sociais de 2017 (IBGE, 2018), apesar de as mulheres representarem mais da metade da população em idade de trabalhar, apenas $52,7 \%$ delas participaram do mercado de trabalho em 2017 , enquanto $72,5 \%$ dos homens estavam trabalhando. Dentre os principais setores da economia que geraram postos de trabalho (agropecuária; indústria; construção; comércio e reparação; administração pública; educação, saúde e serviços sociais; serviços domésticos; e demais serviços), as mulheres ocuparam, preponderantemente, cargos na área da educação, saúde, serviços sociais e serviços domésticos.

\footnotetext{
${ }^{3}$ Os Estudos Culturais devem ser compreendidos como um movimento teórico-político que surge após segunda guerra mundial em vários países do mundo, cujo berço, pelo pensamento dominante, se dá na Inglaterra com a fundação do Centre for Contemporary Cultural Studies (CCCS) na Universidade de Birmingham na Inglaterra, por Richard Hoggart em 1964, bem como com a divulgação de textos de outros estudiosos (COSTA; SILVEIRA; SOMMER, 2003). Caracteriza-se como uma área inter/trans e até antidisciplinar, "onde diferentes disciplinas interatuam, visando ao estudo de aspectos culturais da sociedade"; no momento inicial de sua formação as disciplinas de Literatura Inglesa, Sociologia e História compuseram a interdisciplinaridade; como campo teórico se funda principalmente no marxismo e politicamente, nos movimentos sociais ligados à New Left e com a educação de adultos em salas não convencionais (ESCOSTEGUY, 2006, p. 04).
} 
BERNARDES, C.F.S.; GUIMARÃES, S. F.

Além disso, "receberam menos que os homens, em média, $\mathrm{R} \$ 1.743$, o que representava $77 \%$ do rendimento masculino (R\$ 2.261)" (IBGE, 2018, p. 29).

O próprio IBGE (2018) explica que essas desigualdades entre os sexos masculino e feminino são atribuídas tanto a práticas discriminatórias no mercado de trabalho quanto à divisão, por gênero, dos afazeres domésticos e cuidados: "as mulheres dedicavam, em média, 20,9 horas semanais a afazeres domésticos no domicílio ou em domicílio de parente e/ou cuidados de moradores ou de parentes não moradores, enquanto os homens dedicavam, em média, 10,8 horas a essas atividades" (p. 33).

Tanto para Louro (2003) como para Candau (2011) e Netto (2017) a atribuição da diferença é sempre social e historicamente construída, é dinâmica, está em processo contínuo de construção-descontrução-construção, e perpassa pelas relações de poder, pela ótica de quem a define como diferente. Por exemplo, "em nossa sociedade, devido à hegemonia branca, masculina, heterossexual e cristã, têm sido nomeados e nomeadas como diferentes aqueles e aquelas que não compartilham desses atributos” (LOURO, p.49). Segundo Netto (2017), “[...] toda diferença é uma produção social feita por meio de discursos. O mundo é mais ou menos diverso a partir de certa perspectiva que define, discursivamente, índices de diferenciação" (p. 47).

Candau (2011) afirma que as diferenças são constitutivas dos indivíduos e dos grupos sociais, no entanto, a diferença está em como são reconhecidas e tratadas. As diferenças, "devem ser reconhecidas e valorizadas positivamente no que têm de marcas sempre dinâmicas de identidade, ao mesmo tempo em que combatidas as tendências a transformá-las em desigualdades, assim como a tornar os sujeitos a elas referidos, objeto de preconceito e discriminação" (p. 246).

Pensando o objeto deste estudo que é a intersecção gênero e gestão escolar, os estudos de Candau (2011, p. 241) demonstram que a cultura escolar dominante nas instituições educativas brasileiras, "construída fundamentalmente a partir da matriz político-social e epistemológica da modernidade, prioriza o comum, o uniforme, o homogêneo, considerados como elementos constitutivos do universal". Dessa forma, conclui a autora que as diversas manifestações da diferença, de gênero, étnicas, de orientação sexual, geracional, sensóriomotoras, cognitivas, entre outras, são ignoradas ou consideradas um "problema" a resolver.

Louro (2003) esclarece que a Escola é um locus das diferenças de gênero, sexualidade, etnia, classe, etc, sendo constituída por elas e ao mesmo tempo as produzindo/reproduzindo por meio dos currículos, normas, procedimentos de ensino, teorias, linguagem, materiais didáticos, processos de avaliação, dentre outros. 
Ao longo dessa seção, os estudos nos levam a refletir que as diferenças de gênero são construídas social e historicamente, a partir de um padrão normativo, pela ótica de um pensamento dominante, gerando com isso desigualdades no reconhecimento e no acesso aos direitos que lhes garantem igualdade de oportunidades. Pensando na gestão educacional/escolar, veremos que os marcos jurídicos, em seu contexto social, histórico, político e econômico, também normatizam o perfil dos futuros dirigentes.

\section{O PERFIL DAS (OS) GESTORAS (ES) ESCOLARES NOS MARCOS JURÍDICOS}

A Lei de Diretrizes e Base da Educação Nacional - LDBEN - Lei 9.354 de 1996 (BRASIL, 2019) estabelece no Art. 64 que os trabalhadores em Educação que irão administrar, planejar, supervisionar, inspecionar e orientar processos educativos nos sistemas ou instituições de ensino, tenham formação, em nível superior, nos cursos de Pedagogia ou em nível de Pósgraduação.

A LDBEN de 1996 ainda esclarece que são funções do Magistério (Art. 67, § 2º.), as atividades de docência, as de direção de unidade escolar e as de coordenação e assessoramento pedagógico, todas exercidas por professores e especialistas da Educação Básica. No entanto, há uma centralidade da atividade docente (Art. 67, $\S 1^{\circ}$.), a "experiência docente é pré-requisito para o exercício profissional de quaisquer outras funções de magistério, nos termos das normas de cada sistema de ensino". Sendo que esses profissionais da Educação deverão assumir seus cargos via nomeação por concurso público: os Sistemas de Ensino promoverão a valorização dos profissionais da educação realizando "ingresso exclusivamente por concurso público de provas e títulos" (Art. 67, inciso I).

Essas normatizações estabelecidas pela LDBEN de 1996 definem, de certo modo, o perfil dos gestores educacionais/escolares e a forma como assumirão suas funções: os dirigentes escolares serão professores com formação em nível superior, preferencialmente a licenciatura em Pedagogia, e/ou com formação em nível de Pós-graduação na área da gestão educacional/escolar; sendo sua assunção ao cargo via concurso público de provas e títulos.

Entretanto, frente ao regime de colaboração na organização e gestão da educação Nacional, previsto na LDBEN, os entes Federativos (União, Estados, Distrito Federal e Municípios), com seus respectivos Sistemas de Ensino, possuem a autonomia para definir suas regras complementares quanto à organização da Educação Básica, logo, também poderão definir regras complementares quanto ao perfil do (a) gestor (a) educacional/escolar e sua assunção aos cargos. 
BERNARDES, C.F.S.; GUIMARÃES, S. F.

Como exemplo, o Estado de Minas Gerais definiu a seleção e a eleição direta como critério para a investidura no cargo de direção e vice direção, Resolução da Secretaria Estadual de Educação, n ${ }^{\text {o. }}$ 4127/2019, podendo se candidatar os professores ou especialistas em educação em cargos estáveis; que possuam Certificação Ocupacional de Diretor de Escola Estadual ${ }^{4}$; com formação em Pedagogia ou licenciatura ou bacharelado acrescido de formação pedagógica de docentes; e estar em exercício na escola para a qual pretende candidatar-se por, no mínimo, 2 (dois) anos. Nesse exemplo, além dos docentes, os especialistas também podem se candidatar ao cargo de gestão, cuja formação vai para além da Pedagogia, podem ter outras licenciaturas ou bacharelado com complementação pedagógica.

Vimos que os marcos jurídicos, citados acima, deixam implícito o gênero da função de gestor (a) educacional/escolar, por meio do critério da docência e da formação em licenciatura, principalmente, a Pedagogia. Os indicadores sociais do IBGE (2018) demonstraram que as mulheres com instrução superior ocupam, preponderantemente, funções na área da Educação, Saúde e Serviço social. Veremos, também, que as licenciaturas no Brasil são cursadas, em sua maioria por mulheres, e que os professores da Educação Básica são tipicamente mulheres.

O Censo da Educação Superior no Brasil, ano 2017 (INEP, 2017), explicita que 20\% das matrículas no Ensino Superior referem-se às graduações em licenciaturas, que 70,6\% dos alunos são do sexo feminino e que o curso de Pedagogia recebe o maior número de matrículas (44,7\% ou 710.855). Sobre a paridade de gênero na Educação Superior, a proporção de mulheres que ingressam e concluem o ensino superior é maior (57\% matrículas, $61,1 \%$ concluintes) que a dos homens (43\% matrículas e 38,9\% concluintes). Sobre a preferência de cursos, as mulheres frequentam em primeiro lugar o curso de Pedagogia (660.917 matrículas) e os homens o curso de Direito (392.817 matrículas), apesar do curso de Direito ser o segundo curso de preferência das mulheres, o curso de Pedagogia está em penúltimo lugar na preferência dos homens (19\%.).

Por sua vez, o Censo da Educação Básica em 2017 (CARVALHO, 2018, p.61) demonstrou que "o professor típico brasileiro em 2017 é do sexo feminino (81\%), de raça/cor branca (42\%, principalmente nas regiões Sul e Sudeste) ou parda (25,2\%, principalmente na região Nordeste), e estão alocados, prioritariamente, nas etapas iniciais da educação básica”. Proporcionalmente, há uma participação maior das mulheres na Educação infantil e nos anos iniciais do Ensino Fundamental, em torno de 90\%; e um aumento da participação masculina nos anos finais do Ensino Fundamental e no Ensino médio, em torno de $40 \%$.

\footnotetext{
${ }^{4}$ Segundo a SEE/MG, a Certificação Ocupacional de Diretor de Escola Estadual não constitui concurso público para investidura no cargo. Por meio de prova escrita, avalia conhecimento pedagógico, técnico e as competências necessárias ao satisfatório desempenho do cargo de Diretor de Escola Estadual. Os candidatos que obtiverem 60\% de aproveitamento, comporão um banco de potenciais candidatos ao cargo de diretor.
} 
Sobre a prevalência das mulheres na docência, Vianna (2013) explica que, no Brasil, "desde o século XIX, os homens vão abandonando as salas de aula nos cursos primários e as Escolas Normais vão formando mais e mais mulheres. No final da década de 1920 e início da de 1930, a maioria do magistério primário já era feminina” (p. 165).

Observa-se que o fenômeno da "Feminização" da Educação é objeto de problematização por vários pesquisadores (DEMARTINI; ANTUNES, 1993; ALMEIDA, 1998; LOURO, 2003; WERLE, 2005; GATTI; BARRETTO, 2009; VIANNA, 2013). Alguns autores explicam que esse fato se deve historicamente à conquista das mulheres pela amplificação de seu grau de escolarização; enquanto classe de trabalhadoras, foi uma conquista pelo campo de trabalho; à associação da função docente, principalmente, nos anos iniciais da escolarização como extensão da vida privada, ao papel de cuidadora; à desvalorização da profissão docente e aos baixos salários que levam os homens a privilegiarem outras profissões, sendo a função ocupada, principalmente, por minorias sociais.

As informações trabalhadas ao longo dessa seção, suscitam que o curso de Pedagogia é o principal formador de profissionais da Educação, sendo a Educação Básica eminentemente feminina. Logo, espera-se que os cargos de gestão escolar sejam ocupados preponderantemente por mulheres com formação em Pedagogia.

\section{O PERFIL, A GESTÃO E O GÊNERO DOS DIRIGENTES ESCOLARES}

Há vários questionamentos sobre a ausência de informações na literatura e no Ministério da Educação sobre o perfil e o trabalho das (os) professoras (es) gestoras (es) no Brasil (HEIDRICH, 2017; VIEIRA; VIDAL, 2014; SOUZA; GOUVEIA, 2009). No entanto, observase que os pesquisadores problematizam sobre o tema em nível nacional, a partir dos dados do SAEB - Sistema de Avaliação da Educação Básica ${ }^{5}$ de 2003 (SOUZA, 2007), de 2007 (SOUZA; GOUVEIA, 2010), de 2011 (VIEIRA; VIDAL, 2014) e de 2015 (OLIVEIRA; GIORDANO, 2018) disponibilizados pelo INEP - Instituto Nacional de Educação e Pesquisa Anísio Teixeira/Ministério da Educação.

\footnotetext{
${ }^{5}$ Segundo o INEP (2019), o SAEB abarca um conjunto de avaliações externas aplicadas, bienalmente, nas instituições de ensino públicas e privadas, que permitem indicar a qualidade do ensino na Educação Básica e os fatores que podem interferir nesse desempenho. As avaliações englobam testes cognitivos de Português e Matemática aplicados aos alunos do $5^{\circ}$. e $9^{\circ}$. ano do Ensino Fundamental e $3^{\circ}$. ano do Ensino Médio; testes para aferir os níveis de alfabetização e letramento em Língua Portuguesa (leitura e escrita) e Matemática dos estudantes do $3^{\circ}$ ano do Ensino Fundamental das escolas públicas; e, questionários aos alunos, professores, gestores e aos aplicadores das provas para avaliar os contextos socioeconômico, pedagógico, de gestão, de infraestrutura, dentre outros, que possam interferir na qualidade do ensino. Especificamente, quanto aos gestores eles respondem um questionário com 111 itens referentes à formação profissional, às práticas gerenciais e ao perfil socioeconômico e cultural, servindo de base de dados para os pesquisadores na área da gestão educacional/escolar.
} 
BERNARDES, C.F.S.; GUIMARÃES, S. F.

Não há dúvidas sobre o predomínio, de modo geral, das mulheres ocupando funções de dirigentes escolares, principalmente, na Educação Infantil e anos iniciais do Ensino Fundamental. No entanto, veremos que tanto a progressão na carreira docente, como a assunção aos cargos de gestão são marcadas por desigualdades de gênero.

Segundo Souza (2007), as (os) gestoras (es) das escolas públicas no Brasil, a partir de informações do SAEB 2003, caracterizam-se por serem majoritariamente mulheres (78\%), com mais de 40 anos de idade (65\%), com curso superior (86\%) em Pedagogia (38,8\%) e demais licenciaturas (47,6\%); experientes profissionalmente, com mais de 10 anos de trabalho na educação (85\%); recebendo entre quatro e nove salários mínimos $(58 \%)$; e sendo providos à função em sua maioria democraticamente $(49,3 \%)$, por eleição, eleição mais seleção ou seleção; mesmo havendo as indicações $(45,5 \%)$ políticas, técnicas ou outras, principalmente, nas redes municipais de ensino.

As estatísticas acima tendem a se repetir nos dados do SAEB de 2007 (SOUZA; GOUVEIA, 2010), 2011 (VIEIRA; VIDAL, 2014) e 2015 (OLIVEIRA; GIORDANO, 2018). Na base de dados do SAEB de 2007, as mulheres ocupavam 76,7\% dos cargos de dirigente escolar e os homens $23,3 \%$; a maioria dos gestores possuíam instrução superior (94\%), sendo a Pedagogia $(36,4 \%)$ o curso mais frequente, principalmente para os anos iniciais da escolarização e, posteriormente, as demais licenciaturas (37,8); e foram providos democraticamente $(49,1 \%)$ por eleição, eleição mais seleção ou seleção, havendo as indicações $(44,9 \%)$, sejam política, técnica ou outras.

Nos dados do SAEB de 2011 (VIEIRA; VIDAL, 2014), 79,4\% dos postos de gestão foram assumidos pelas mulheres e 18,4\% pelos homens; a maioria com idade entre 40 a 49 anos; sendo a formação inicial, preponderante, o curso de Pedagogia $(39,4 \%)$ e outras licenciaturas $(35,1 \%)$. Os processos democráticos de provimento ao cargo (seleção, eleição e seleção com eleição) totalizaram $42,8 \%$, e $45,9 \%$ dos diretores chegaram ao cargo por algum tipo de indicação política, técnica ou outras.

Por fim, Oliveira e Giordano (2018, p. 07) comparando os microdados do SAEB de 2007 a 2015, verificou-se que a "grande maioria é constituída por pessoas do sexo feminino (cerca de $80 \%$ ao longo do período pesquisado, enquanto o índice para o sexo masculino se manteve em torno de 20\%)", havendo um pequeno aumento da participação masculina (próxima a 2\%) desde 2007. As autoras também verificaram crescimento na formação inicial e continuada das (os) diretoras (es) ao longo dos anos, a maior parte delas (es) possui ensino superior em Pedagogia ou outras licenciaturas (entre $70 \%$ e $80 \%$ ) e especialização (indo de 57,8\%, em 2007 para 74,6\%, em 2015). Sobre o acesso ao cargo, verificaram que as formas mais democráticas (seleção e/ou eleição) tem diminuído ao longo dos anos (47,9\% em 2007 a 
43,2\% em 2015) e aumentando o acesso por indicações (políticas e/ou técnicas), indo de 42,8\% em 2007 a $46 \%$ em 2015.

Dentre os autores citados que se basearam no banco de dados do SAEB, apenas Souza (2007) problematizou a relação de gênero com a função de diretor (a) escolar, demonstrando fortes marcas de desigualdades entre os gêneros. Foram problematizados os seguintes aspectos: prevalência de homens/mulheres ao longo dos níveis de ensino da Educação Básica; idade e tempo de serviço com que ascendem aos cargos de direção; faixa salarial entre homens e mulheres; e algumas práticas gerenciais.

Quanto à prevalência de homens/mulheres ao longo dos níveis de ensino da Educação Básica, segundo Souza (2007), há maior presença das mulheres em todos os anos/níveis de ensino, principalmente na Educação Infantil e anos iniciais do Ensino Fundamental, chegando a $83 \%$ de presença. No entanto, há uma crescente participação dos homens nos anos finais da Educação Básica. No Ensino Médio, por exemplo, eles dirigem 31\% das escolas e as mulheres (68\%). Há diferenças também por região do Brasil, as regiões mais economicamente desenvolvidas como Sul e Sudeste, têm as maiores taxas de participação de mulheres nas direções escolares, enquanto que o Norte e o Nordeste apresentam as maiores taxas de homens diretores (SOUZA, 2007).

Ainda nos anos/níveis de ensino, Souza (2007) salienta que, comparando a proporção entre o número de professores e o número de diretores, há um predomínio de homens nas direções e as mulheres com mais frequência nas salas de aula. Isso foi mais marcante no quarto ano do Ensino Fundamental, houve um percentual de 16,7\% de diretores homens para um universo de 9,4\% professores, ou seja, houve poucos professores homens no $4^{\circ}$. ano do Ensino Fundamental e a maioria deles estavam em cargos de direção e não na sala de aula. O autor fundamenta que esse fato decorre possivelmente pelo poder que o domínio masculino tem nas relações mais cotidianas, levando os homens, em profissões eminentemente femininas, aos cargos de direção.

No que diz respeito à idade e tempo de serviço com que ascendem aos cargos de direção, os homens assumem posições de comando nas escolas com menos idade (35-39 anos) que as mulheres (40-45 anos) e com menos experiência educacional, cerca de 47,6\% dos diretores homens possuem menos do que 15 anos de trabalho na educação, enquanto que aproximadamente $70 \%$ das diretoras possuem mais de 15 anos de experiência profissional e 44\% delas têm mais de 20 anos de trabalho educacional, suscitando que as mulheres assumem a função de dirigente mais tardiamente se comparadas aos homens. Souza (2007) também problematiza essa situação em função do domínio do sexo masculino, associando-o a postos de 
BERNARDES, C.F.S.; GUIMARÃES, S. F.

comando, de controle. Por outro, podemos problematizar que a mulher assume funções de direção, tardiamente, devido ao tempo de vida que desprende com cuidados na maternidade, no casamento e com outros familiares, pois como evidenciou o IBGE (2018), as mulheres dedicam o dobro de horas aos afazeres domésticos e outros cuidados.

Apesar da previsão de que a maioria dos Sistemas de Ensino no Brasil possui um plano de carreira docente, apesar do universo de gestores serem eminentemente feminino, as mulheres ganham menos que os homens para desempenhar a mesma função. $\mathrm{O}$ maior grupo de diretoras mulheres $(30,2 \%)$ se encontra na faixa salarial de 4,1 a 6 salários mínimos, e entre os homens o maior grupo (30,5\%) está na faixa salarial de 6,1 a 9 salários (SOUZA, 2007). O autor não deixa esclarecido os motivos dessa diferença, mas talvez se explique pelo fato de haver muitas indicações políticas, principalmente nos municípios; do cargo ser comissionado, havendo variações nas comissões; e, talvez, por não haver em todos os sistemas de ensino um plano de cargos e salários que normatize a função/salário das (os) diretoras (os).

Por fim, quanto a algumas práticas de gestão, as mulheres indicam desenvolver uma gestão mais participativa do que os homens. Conforme Souza (2007), há uma "pequena vantagem no número de escolas dirigidas por mulheres nas quais o Conselho Escolar funciona ativamente, assim como há um maior número de escolas dirigidas por homens nas quais o Conselho Escolar não existe ou não foi reunida nenhuma vez em 2003” (p.269). As mulheres também buscam a participação da comunidade escolar na construção do Projeto Político Pedagógico das escolas, $56,7 \%$ das mulheres incluem ativamente os professores na construção do PPP, enquanto $48 \%$ dos homens diretores o fazem.

Souza (2007) finaliza que "os aspectos técnicos, pedagógicos, políticos da gestão escolar parecem reproduzir as formas masculinas do mundo social e, consequentemente, as desigualdades de gênero" (p. 310). Interessante sinalizar que estudos anteriores (DEMARTINI; ANTUNES, 1993) e outros mais recentes (CORRÊA, 2010; COUTINHO, 2018) coadunam com Souza (2007), a docência é eminentemente feminina, mas a carreira se mostra masculina.

Demartini e Antunes (1993) realizaram uma pesquisa com 41 professores do Estado de São Paulo que se formaram e lecionaram no Magistério primário no momento histórico da Primeira República Brasileira (1889-1930). As autoras afirmam que já nas primeiras décadas do século XX, ocorria a feminização do magistério no Brasil, fato que atravessou sou amostra de pesquisa, dos 41 entrevistados, 8 foram homens e 33 mulheres. Os relatos dos participantes demonstraram que o exercício do Magistério primário era feminino, mas a carreira era masculina, ou seja, os homens que cursavam o Magistério pouco lecionavam, rapidamente ascendiam a funções técnicas e de direção nas escolas e/ou nas redes de ensino, bem como passavam a lecionar e coordenar a formação de professores. 
Passados aproximadamente 100 anos, essa condição parece se manter. Corrêa (2010) fez uma pesquisa no banco de dados do SAEB de 2007 e acompanhando as eleições para diretores escolares no município de Curitiba em 2008, verificou a prevalência das mulheres no exercício da docência e nos cargos de direção. Entretanto, comparando o número de professores com a de diretores, proporcionalmente, há mais homens nos cargos de direção, ocorrendo assim o fenômeno do "teto de vidro" (glass ceiling) ${ }^{6}$ na carreira docente: "o fato de a Educação ser uma profissão 'feminizada' não impede os homens de assumirem os cargos de mando, como se fosse o seu lugar natural", mesmo sendo mais jovens, menos experientes e menos qualificados (CORRÊA, 2010, p. 90).

Coutinho (2018) também empreendeu uma pesquisa sobre o perfil e práticas de gestão de diretoras escolares para o município de Uberlândia/MG a partir dos dados do SAEB 2003, 2007 e 2015, além de entrevistas com oito diretoras do município. A autora confirma que no município de Uberlândia/MG há prevalência das mulheres nas funções de diretoras escolares, seguindo a tendência a nível nacional. Observou-se também, que as responsabilidades pela criação da prole e a sobrecarga de trabalho profissional e doméstico/familiar são elementos que dificultam a ascensão das mulheres aos cargos de gestão, uma vez que as atividades do domínio doméstico ainda são atribuídas, principalmente, às mulheres. A autora conclui que o sexismo e a cultura de dominação masculina que permeiam as sociedades ocidentais marcam as práticas de gestão das diretoras investigadas ao impor-lhes uma adequação subjetiva à identidade social feminina que prioriza a esfera privada, como se a gestão fosse naturalmente masculina.

\section{CONSIDERAÇÕES FINAIS}

A trajetória desse texto traduziu uma busca por respostas para as diferenças de gênero nas funções de gestão, em específico a gestão escolar, partindo de uma representação que a mulher seria reconhecida e valorizada em suas diferenças: Mulher estudiosa, Mulher pensante, Mulher mãe, Mulher esposa, Mulher filha, Mulher militante, Mulher líder. Com tantos papéis sociais, refletimos sobre o quanto a Mulher ainda precisa se assoberbar com a excelência em tantas tarefas para ser reconhecida e valorizada.

Os estudos brasileiros sobre o perfil das (os) gestoras (es) escolares parecem indicar um predomínio da concepção de gênero sexista que associa o domínio público, o controle e a

\footnotetext{
${ }^{6}$ Corrêa (2010) explica que o conceito do teto de vidro (glass ceiling) surgiu nos Estados Unidos, na década de 80, para descrever a barreira profissional que, de tão sutil, é transparente, impedindo muitos profissionais de ascenderem na carreira profissional dentro das organizações. No caso das mulheres, o teto de vidro pode estar nas brincadeiras e comentários, nas políticas administrativas, quase sempre favoráveis aos homens e na maneira como o espaço é utilizado e disponibilizado, sem levar em conta as necessidades femininas.
} 
BERNARDES, C.F.S.; GUIMARÃES, S. F.

liderança desses espaços como sendo eminentemente masculinos e como tal, quem os ocupar, para serem legitimados deverão imbuir-se dessas representações. Ora, os Estudos feministas e os Estudos culturais mostram que construímos nossa identidade de gênero, como nossas outras múltiplas identidades, nas e pelas relações sociais em seu contexto cultural, histórico, político, econômico, os quais estabelecem padrões do aceitável, do normal. Dessa forma, poderíamos dizer que mesmo com a crescente escolarização, a participação no mercado de trabalho, a autonomia financeira e emocional, enfim, com o empoderamento feminino, ainda coexiste em nós mulheres, o modelo sexista que institui as atividades públicas ao masculino e as atividades privadas do lar ao feminino.

Acreditando na capacidade dos sujeitos de ressignificarem a si mesmos ao longo da sua história e pensando na finalidade da Educação de formação social, sigo o pensamento de Guacira Louro de que é "indispensável questionar não apenas o que ensinamos, mas o modo como ensinamos e que sentidos nossos/as alunos/as dão ao que aprendem” (2003, p. 64), procurando perceber o sexismo, o racismo e o etnocentrismo que nossa linguagem e nossas ações carregam e institui.

Os resultados das pesquisas que se basearam nos microdados do SAEB (SOUZA, 2007; SOUZA; GOUVEIA, 2010; CORRÊA, 2010; VIEIRA; VIDAL, 2014; COUTINHO, 2018; OLIVEIRA; GIORDANO, 2018) suscitam outras problematizações, uma vez que somente alguns autores associaram a gestão educacional/escolar ao gênero, tais como:

1) o perfil das (os) diretoras (es) escolares dos anos anteriores (2007 a 2015) se mantém nos microdados do SAEB de 2017?

2) a relação entre a forma de provimento ao cargo e gênero, ou seja, as mulheres ascendem à função mais democraticamente (eleição, seleção) ou por indicações políticas e/ou técnicas?

3) a relação da maternidade e do casamento com a ascensão e o exercício da gestão escolar: qual o percentual de mulheres solteiras e casadas que assumem a gestão? A maternidade e o casamento são impeditivos para o exercício da carreira profissional? Como administram a vida privada com o trabalho?

4) como a mulher lida com a face política da gestão, com os jogos de poder, uma vez que lidará com múltiplos interesses, sejam da comunidade escolar, dos superiores nos sistemas de ensino e do governo com suas políticas educacionais?

5) há diferenças entre homens e mulheres no exercício da liderança? A gestão feminina propicia melhores resultados educacionais? 
6) também se pergunta qual o perfil dos dirigentes educacionais que ocupam os escalões superiores da Educação Nacional e que pensam o processo educacional. Há prevalência de mulheres?

7) pensando a identidade de gênero abarcando outras múltiplas identidades (etnia, raça/cor, orientação afetivo sexual, nacionalidade, estrato social, religiosa, dentre outros), qual o perfil das mulheres que assumem a gestão escolar? São brancas, de classe média/alta, heterossexuais, cristãs?

As respostas a todas essas problematizações ficam limitadas com os microdados do SAEB, uma vez que o questionário contextual ${ }^{7}$ aplicado às (aos) diretoras (es) não faz, por exemplo, perguntas sobre o estado civil, a orientação afetiva sexual, a maternidade, a religião dos participantes e o estrato social ao qual pertencem. Portanto, estudos com essa temática sugerem pesquisas de natureza quantitativa e qualitativa, utilizando os microdados do SAEB e pesquisas empíricas, buscando ouvir as (os) gestoras (os) das unidades escolares, bem como dos sistemas de ensino e órgãos de apoio, sobre sua trajetória profissional na gestão.

\section{REFERÊNCIAS}

ALMEIDA, Jane Soares de. Mulher e educação: a paixão pelo possível? São Paulo: Editora UNESP, 1998. Disponível em:

http://www.dominiopublico.gov.br/download/texto/up000028.pdf. Acesso em: 10 fev. 2019.

BRASIL. Constituição (1988). Constituição da República Federativa do Brasil: 1988. Presidência da República, Casa Civil, 2019. Disponível em: http://www.planalto.gov.br/ccivil_03/Constituicao/Constituicao.htm. Acesso em: 21 jan. 2019.

BRASIL. Lei $n^{o .9}$ 9.394, 20 de dezembro de 1996. Estabelece as Diretrizes e Bases da Educação Nacional. Presidência da República, Casa Civil, Brasília, 2019. Disponível em: http://www.planalto.gov.br/ccivil_03/Leis/L9394.htm. Acesso em: 24 jan. 2019.

CANDAU, Vera. Maria Ferrão. Diferenças culturais, cotidiano escolar e práticas pedagógicas. Currículo sem Fronteiras, v.11, n.2, p. 240-255, jul/dez 2011. Disponível em:

http://www.curriculosemfronteiras.org/vol11iss2articles/candau.pdf. Acesso em 07 ago. 2018.

CARVALHO, Maria Regina Viveiros de. Perfil do professor da educação básica. Brasília: Instituto Nacional de Estudos e Pesquisas Educacionais Anísio Teixeira, 2018. 67 p. (Série Documental Relatos de Pesquisa). Disponível em: http://portal.inep.gov.br/informacao-dapublicacao/-/asset_publisher/6JYIsGMAMkW1/document/id/1473981. Acesso em: $10 \mathrm{fev}$. 2019.

\footnotetext{
${ }^{7}$ O questionário aplicado aos Diretores em 2017 pode ser acessado no endereço eletrônico no site do INEP/ME: http://download.inep.gov.br/educacao_basica/saeb/aneb_anresc/quest_contextuais/2017/questionario_diretor_20 $\underline{17 . p d f}$
} 
BERNARDES, C.F.S.; GUIMARÃES, S. F.

CORRÊA, Vanisse Simone Alves. Gestão escolar e gênero: o fenômeno do teto de vidro na educação brasileira. Dissertação (Mestrado em Educação: Gestão e Políticas Públicas) Universidade Federal do Paraná, Curitiba, 2010. Disponível em:

http://www.ppge.ufpr.br/teses/M10_correa.pdf. Acesso em: 10 fev. 2019.

COSTA, Marisa Vorraber; SILVEIRA, Rosa Hessel; SOMMER, Luís Henrique. Estudos Culturais, Educação e pedagogia. Revista Brasileira de Educação, Rio de Janeiro, n. 23, p. 36-61, agosto de 2003. Disponível em: http://www.scielo.br/pdf/rbedu/n23/n23a03.pdf. Acesso em: 10 de jul. 2016.

COUTINHO, Priscila Munhoz. Um perfil profissional de diretoras escolares: trabalho, gênero e educação em escolas do ensino fundamental de Uberlândia. Dissertação (Mestrado em Ciências Sociais) - Universidade Federal de Uberlândia, Uberlândia, 2018. Disponível em: https://repositorio.ufu.br/handle/123456789/22417. Acesso em 10 fev. 2019.

DEMARTINI, Zeila, Brito Fabri; ANTUNES, Fátima Ferreira. Magistério primário: profissão feminina, carreira masculina. Cadernos de Pesquisa, São Paulo, n. 86, p. 05-14, ago. 1993. Disponível em: http://publicacoes.fcc.org.br/ojs/index.php/cp/article/view/934. Acesso em: 26 jan. 2019.

ESCOSTEGUY, Ana Carolina. Os Estudos Culturais. Cartografias (PUC-RS), PPGCS, agosto 2006.

GATTI, Bernardete Angelina.; BARRETTO, Elba Siqueira Sá (Org.). Professores do Brasil: impasses e desafios. Brasília: UNESCO, 2009.

HEIDRICH, Gustavo. Por que ninguém sabe quantos gestores escolares existem no Brasil? Gestão Escolar, São Paulo, 17 abr. 2017. Disponível em:

https://gestaoescolar.org.br/conteudo/1787/ninguem-sabe-quantos-gestoresescolares- o-brasiltem. Acesso em: 02 fev. 2019.

IBGE - INSTITUTO BRASILEIRO DE GEOGRAFIA E ESTATÍSTICA. Síntese de Indicadores sociais: uma análise das condições de vida da população brasileira. Rio de Janeiro: IBGE, 2018. 151 p. - (Estudos e pesquisas. Informação demográfica e socioeconômica, n. 39). Disponível em: https://biblioteca.ibge.gov.br/index.php/bibliotecacatalogo?view=detalhes\&id=2101629. Acesso em: 11 de out. 2018.

IBGE- INSTITUTO BRASILEIRO DE GEOGRAFIA E ESTATÍSTICA. Boletim Educação 2017. Pesquisa Nacional por Amostra de Domicílios Contínua, PNAD -C. Disponível em: https://biblioteca.ibge.gov.br/visualizacao/livros/liv101576_informativo.pdf. Acesso em: 11 de out. 2018.

INEP - INSTITUTO NACIONAL DE EDUCAÇÃO E PESQUISAS ANÍSIO TEIXEIRA/ Ministério da Educação. Censo da Educação Superior 2017. Brasília: Diretoria de Estatísticas Educacionais/INEP/ME, 2018. Disponível em: http://portal.mec.gov.br/docman/setembro2018-pdf/97041-apresentac-a-o-censo-superior-u-ltimo/file. Acesso em: 20 jan. 2019.

INEP - INSTITUTO NACIONAL DE EDUCAÇÃO E PESQUISAS ANÍSIO TEIXEIRA/ Ministério da Educação. Sistema de Avaliação da Educação Básica - SAEB. Disponível em: http://portal.inep.gov.br/web/guest/educacao-basica/saeb. Acesso em 10 fev. 2019. 
LAVILLE, Christian; DIONNE, Jean. A construção do saber: manual de metodologia da pesquisa em ciências humanas. Tradução Heloisa Monteiro e Francisco Settineri. Porto Alegre: Artmed; Belo Horizonte: Editora UFMG, 2007.

LOURO, Guacira Lopes. Gênero, sexualidade e educação: uma perspectiva pósestruturalista. 6 ed. Petrópolis: Vozes, 2003. Disponível em: https://bibliotecaonlinedahisfj.files.wordpress.com/2015/03/genero-sexualidade-e-educacaoguacira-lopes-louro.pdf. Acesso em 10 fev. 2019.

MARCONI, Marina de Andrade.; LAKATOS, Eva Maria. Fundamentos de metodologia científica. 7 ed. São Paulo: Atlas, 2010.

NETTO, Michel Nicolau. A diferença do discurso da diversidade. Contemporânea, v. 7, n. 1, p. 39-61, jan./jun. 2017. Disponível em:

http://www.contemporanea.ufscar.br/index.php/contemporanea/article/view/516. Acesso em: 10 fev. 2019.

OLIVEIRA, Ana Cristina Prado de.; GIORDANO, Emília. O perfil dos diretores de escolas públicas no Brasil. Revista Educação Online, Rio de Janeiro, n. 27, p. 49-72, jan./abr. 2018. Disponível em: http://educacaoonline.edu.puc-rio.br/index.php/eduonline/article/view/376. Acesso em 15 maio 2019.

SECRETARIA ESTATUDAL DE EDUCAÇÃO DE MINAS GERAIS - SEE/MG.

Resolução SEE $n^{\circ}$ 4.127, 23 de abril de 2019. Estabelece normas para escolha de servidor ao cargo de diretor e à função de vice-diretor de escola estadual de Minas Gerais. Diário do Executivo, Belo Horizonte, Caderno 01, p. 14-28, 24 abril 2019. Disponível em: http://jornal.iof.mg.gov.br/xmlui/handle/123456789/218318. Acesso em: 26 maio 2019.

SOUZA, Ângelo Ricardo de.; GOUVEIA, Andréa Barbosa. Diretores de escolas públicas: aspectos do trabalho docente. Educar em Revista, Curitiba, n. especial 1, p. 173-190, 2010. Disponível em: http://www.scielo.br/pdf/er/nspe_1/09.pdf. Acesso em: 22 jan. 2019.

SOUZA, Ângelo Ricardo de. Perfil da Gestão Escolar no Brasil. 2006. 333f. Tese (Doutorado em Educação: História, Política, Sociedade) - Pontifícia Universidade Católica de São Paulo, São Paulo, 2007. Disponível em: https://tede2.pucsp.br/bitstream/handle/10567/1/ANGELO\%20RICARDO\%20DE\%20SOUZ A.pdf. Acesso em: 22 jan. 2019.

VIANNA, Claudia Pereira. A feminização do magistério na educação básica e os desafios para a prática e a identidade coletiva docente. In: YANNOULAS, Silvia Cristina (Org.). Trabalhadoras: análise da feminização das profissões e ocupações. Brasília: Abaré, 2013. p. 159-180. Disponível em: http://www.producao.usp.br/handle/BDPI/44242. Acesso em: 10 fev. 2019.

VIEIRA, Sofia Lerche; VIDAL, Eloisa Maia. Perfil e formação de gestores escolares no Brasil. Dialogia, São Paulo, n. 19, p. 47-66, jan./jun. 2014. Disponível em: https://www.researchgate.net/publication/314819918_Perfil_e_Formacao_de_Gestores_Escol ares_no_Brasil. Acesso em: 22 jan. 2019.

WERLE, Flávia Obino Corrêa. Práticas de gestão e feminização do magistério. Cadernos de Pesquisa, São Paulo, v. 35, n. 126, p. 609-634, dez. 2005. Disponível em: 


\section{SOBRE AS AUTORAS}

Carliene Freitas da Silva Bernardes é doutoranda em Educação pela Universidade de Uberaba, mestre e graduada em Psicologia pela Universidade Federal de Uberlândia. É docente na Universidade Federal do Tocantins/Tocantinópolis.

E-mail: carlienefreitas@uft.edu.br

Selva Fonseca Guimarães tem doutorado e mestrado em História Social pela Universidade de São Paulo e graduação em História pela Universidade Federal de Uberlândia. Realizou pós-doutorado em Educação pela Unicamp e Estágio Sênior em Didactica de las Ciencias Sociales na Universidad Autonoma de Barcelona. Pesquisadora de Produtividade do CNPq desde 2003. Atualmente é professora colaboradora voluntária do Programa de Pós-graduação em Educação da Universidade Federal de Uberlândia e professora permanente do Programa de Pós-graduação em Educação da Universidade de Uberaba.

E-mail: selva.guimaraes@uniube.br 